\title{
Características físico-químicas de abacaxi submetido à tecnologia de radiação ionizante como método de conservação pós-colheita
}

\author{
Physico-chemical characteristics of pineapple submitted to ionizing \\ radiation technology as a method of post-harvest conservation \\ Josenilda Maria da SILVA ${ }^{1 *}$, Juliana Pizarro SILVA², Marta Helena Fillet SPOTO²
}

\section{Resumo}

A qualidade pós-colheita do abacaxi da cultivar Smooth Cayenne foi avaliada quando os frutos foram irradiados com doses de 100 e $150 \mathrm{~Gy}$, tendo a dose 0 como controle, e os frutos armazenados durante os períodos de 10,20 e 30 dias, à temperatura de $12{ }^{\circ} \mathrm{C}( \pm 1)$ e $85 \%( \pm 5)$ de umidade relativa. Os frutos foram colhidos quando fisiologicamente desenvolvidos. Análises físico-químicas foram realizadas a cada período de armazenamento com o objetivo de obter informações dos efeitos da radiação ionizante sobre as características de qualidade do fruto. As doses de radiação ionizante aplicadas tiveram pouca influência significativa nas características físico-químicas do abacaxi, porém, com melhores resultados quando comparados com a dose controle. O período de 20 dias de armazenamento mostrou ser ideal para o desenvolvimento das principais características de qualidade pós-colheita do fruto, enquanto que o armazenamento por 30 dias foi considerado longo por prejudicar a qualidade do abacaxi.

Palavras-chave: irradiação de frutos; abacaxi; conservação pós-colheita.

\begin{abstract}
The post-harvest quality of pineapple, Smooth Cayenne variety, was evaluated after fruits were gamma-irradiated at 100 and 150 Gy doses. Control samples were non-treated fruits ( 0 Gy dose). Fruits were stored for 10,20 and 30 days at $12{ }^{\circ} \mathrm{C}( \pm 1)$, at a relative humidity of $85 \%$ $( \pm 5)$. Pineapples were harvested at the physiologic developmental stage. Physico-chemical analyses were conducted for each storage period to obtain information on the effects of the irradiation treatment on fruit quality. The doses of ionizing radiation applied had little significant influence on the physico-chemical characteristics of the pineapple. However, they exhibited better results when compared to the control dose. The period of twenty days of storage was ideal for the development of the main post-harvest quality characteristics of the fruit, while storage for thirty days was considered too long, being deleterious to pineapple quality.

Keywords: irradiation of fruits; pineapple; post-harvest conservation.
\end{abstract}

\section{Introdução}

O abacaxi ocupa a oitava posição mundial em produção e a décima primeira em área colhida, sendo cultivado em mais de 70 países. O continente americano é o segundo maior produtor e o Brasil ocupa o terceiro lugar, com plantio distribuído por todo o território. As regiões Nordeste e Sudeste obtêm o maior cultivo, porém, a planta encontra excelentes condições para o seu desenvolvimento e produção em quase todos os territórios brasileiros (BRASIL, 2000; MORGADO; AQUINO; TERRA, 2004; PONTES THÉ et al., 2001).

Os frutos, de uma forma quase geral, necessitam de cuidados pós-colheita devido à ocorrência de várias alterações bioquímicas caracterizadas por um contínuo processo de modificações metabólicas que levam ao desenvolvimento de importantes características da qualidade sensorial, que termina com a senescência (FINGER; VIEIRA, 1997).
Alterações pós-colheita são causadas por diversos fatores, destacando-se a alta taxa respiratória. Esta influencia diretamente nas mudanças metabólicas, na biossíntese e ação do etileno e na mudança composicional dos frutos. O etileno, hormônio produzido principalmente nos frutos climatéricos, tem sua ação fisiológica em quantidade de 0,1 ppm, a qual acelera a respiração, e com isso inicia uma seqüência de reações químicas. Essas reações não podem ser interrompidas, mas podem ser controladas dentro de determinados limites, mediante procedimentos pós-colheita (CHITARRA; CHITARRA, 1990; YANG; HOFFMAN, 1984).

No decorrer dos anos, diversas técnicas com a finalidade de manter a qualidade e aumentar a vida útil dos frutos vêm sendo pesquisadas. Essas técnicas podem ser aplicadas isoladamente

Recebido para publicação em 22/9/2006

Aceito para publicação em 17/12/2007 (001864)

${ }^{1}$ Centro de Energia Nuclear na Agricultura - CENA, Universidade de São Paulo - USP, Av. Centenário, 303, CEP 13400-970, Piracicaba - SP, Brasil,

E-mail: jmnilda@yahoo.com.br

${ }^{2}$ Escola Superior de Agricultura Luiz de Queiroz - ESALQ, Universidade de São Paulo - USP, Brasil

${ }^{*}$ A quem a correspondência deve ser enviada 
ou em conjunto para se obter melhores resultados na qualidade final do produto.

A aplicação da radiação ionizante com objetivos de desinfestar e inibir brotação nos produtos agrícolas tem aumentado significativamente nas últimas décadas. Essa tecnologia é reconhecida por alguns pesquisadores como um método seguro e econômico, contribuindo para uma maior aceitação e aplicação dessa técnica nos alimentos em todo o mundo, principalmente nos frutos frescos, cuja exportação muitas vezes é limitada devido às exigências impostas relacionadas à segurança fitossanitária (MARINHUACHACA et al., 2002; NETO, 1997; PCZCZOLA, 1992).

A radiação ionizante, quando aplicada em doses baixas, tem se mostrado como um método efetivo para prolongar a vida comercial dos frutos por retardar os processos de amadurecimento e senescência. Entretanto, como em qualquer outro tratamento pós-colheita com intuito de conseguir melhor manutenção da qualidade, para se obter resultados satisfatórios no uso da radiação ionizante é necessário que a dose aplicada não venha prejudicar as principais características de qualidade do fruto, por isso adequar a dose ideal constitui um desafio para todos os pesquisadores da área, uma vez que os resultados podem sofrer influências de diversos fatores intrínsecos e extrínsecos. Também, a aplicação de uma dose inadequada pode trazer vários resultados indesejáveis ao fruto, como amadurecimento irregular, escurecimento da polpa e da casca, além de alterações no sabor (DEL MASTRO, 1999; MURRAY, 1990; SILVA; DOMARCO, 2004).

O presente trabalho teve como principal objetivo observar as alterações nas características físico-químicas de abacaxi da cultivar Smooth Cayenne quando submetida às doses de $100 \mathrm{e}$ $150 \mathrm{~Gy}$, associada à temperatura refrigerada de $12{ }^{\circ} \mathrm{C}$ e $85 \%$ de umidade relativa, durante os períodos de 10,20 e 30 dias de armazenamento.

\section{Material e métodos}

Os frutos foram colhidos com maturação fisiológica completamente desenvolvida e coloração da casca com região basal da cor verde clara para verde escura (PY; TISSEAU, 1965).

Utilizou-se o radiador destinado à pesquisa, com fonte de Cobalto-60, taxa de dose de $175 \mathrm{~Gy} / \mathrm{h}$ e atividade mínima de $2.189 \times 10^{10} \mathrm{~Bq}$.

Frutos controle e irradiados com doses de 100 e 150 Gy, foram acondicionados em caixas de papelão com capacidade para seis frutos na horizontal, e armazenados à temperatura de $12{ }^{\circ} \mathrm{C}( \pm 1)$ e $85 \%( \pm 5)$ de umidade relativa durante os períodos de 10, 20 e 30 dias. Totalizando 9 grupos com 12 frutos cada.

Todas as análises foram realizadas na rodela extraída da região mediana equatorial do fruto, com $\pm 2 \mathrm{~cm}$ de espessura, sem o miolo central, e depois de trituradas em liquidificador doméstico foram congeladas para análises posteriores. Foram realizadas três repetições por amostra.

\subsection{Firmeza da polpa (N)}

Realizada com penetrômetro digital, marca TR-Turoni, acoplado a um suporte e ponteira plana de $8 \mathrm{~mm}$ de diâmetro.
As leituras foram distribuídas uniformemente na região mediana equatorial do fruto após retirada de $\pm 0,2 \mathrm{~cm}$ de espessura da casca.

\subsection{Percentual de área com manchas na polpa}

Foi realizado imediatamente após o corte na região mediana equatorial do fruto. Uma folha de plástico transparente foi colocada sobre o local cortado e fez-se um contorno com um lápis marcador sobre a área do fruto e a área com mancha. As folhas foram depois fotocopiadas, as áreas cortadas e pesadas em balança de precisão e aplicadas na fórmula:

\section{$\mathrm{A}=\mathrm{AP} \times \mathrm{PX} / \mathrm{pp}$}

em que: $\mathrm{A}=$ área equatorial do fruto $\mathrm{em}^{\mathrm{cm}}$

$\mathrm{AP}=$ área total do papel ofício $\mathrm{em} \mathrm{cm}^{2}$

$\mathrm{PX}=$ peso do papel ofício correspondente à área total equatorial do fruto

$\mathrm{pp}=$ peso total do papel ofício

Com os resultados da área equatorial do fruto fez-se o mesmo procedimento para determinação da área com mancha, em que:

$\mathrm{A}=$ área com mancha

$\mathrm{AP}=$ área do fruto

$\mathrm{PX}=$ peso do papel ofício correspondente à área com mancha

$\mathrm{pp}=$ peso da área total do fruto

\subsection{Cor da polpa $\left(L^{\star}, a^{\star} e b^{\star}\right)$}

Realizadas com o colorímetro Minolta Collor, modelo CR-300, operando no sistema iluminante D65 e observador padrão $2^{\circ}$. As leituras foram realizadas logo após o corte do fruto na região mediana equatorial, entre a extremidade e o miolo central. Foram realizadas duas leituras em lados opostos. Seguiu as recomendações especificadas por McGuirre (1992).

\subsection{Sólidos solúveis totais $\left({ }^{\circ} \mathrm{Brix}\right)$}

Os sólidos solúveis totais foram determinados no suco. Utilizou-se o refratômetro da marca ATAGO, modelo PZO RR11, Nr. 20700, 0 - $35^{\circ}$ Brix, com compensação de temperatura a $20^{\circ} \mathrm{C}$. Foram seguidas as normas especificadas pelo Instituto Adolfo Lutz (IAL, 1985).

\subsection{Acidez total titulável (\% de ácido cítrico)}

Determinada no suco pelo procedimento eletrométrico e titulometria com solução de $\mathrm{NaOH}$ 0,1 N. A titulação foi efetuada até o $\mathrm{pH}$ atingir $\pm 8,2$. Foram seguidas as normas especificadas pelo Instituto Adolfo Lutz (IAL, 1985).

\subsection{Razão sólidos solúveis/acidez titulável}

Determinada pela divisão dos valores encontrados dos sólidos solúveis e da acidez titulável. 


\subsection{Teor de ácido ascórbico $\left(m g .100 \mathrm{~mL}^{-1}\right)$}

O teor de ácido ascórbico foi determinado no suco. Utilizou-se a solução do ácido oxálico $0,4 \%$ como estabilizador e 2,6-diclorofenolindofenol na titulação. Seguiu a metodologia especificada por Carvalho et al. (1990).

\subsection{Teores das clorofilas a, b e total na casca ( $\mu g . g^{-1}$ de MF)}

Utilizou-se o método descrito por Arnon (1949), que apresenta como solução extratora a acetona $80 \%$. Quantidade de $0,5 \mathrm{a} 1 \mathrm{~g}$ de casca fresca, com espessura de $\pm 1 \mathrm{~mm}$ distribuída na região mediana equatorial do fruto, foi macerada, e adicionados $10 \mathrm{~mL}$ da solução extratora. A solução ficou em frasco escuro e tampado durante 12 horas em geladeira doméstica, depois foi filtrada em papel de filtro e realizada a leitura a 645 e $663 \mathrm{~nm}$ no espectrofotômetro.

Os valores obtidos das absorvâncias foram colocados nas Equações 1, 2 e 3:

Clorofila $\mathrm{a}=12,7 \times$ Abs. (663) $-2,69 \times$ Abs. (645)

Clorofila $b=22,9 \times$ Abs. (645) $-4,68 \times$ Abs. (663)

Clorofila total $=$ Clorofila $\mathrm{a}+$ Clorofila $\mathrm{b}$

Os resultados encontrados foram multiplicados pelo total de diluição com o extrator.

\subsection{Análise dos dados}

Utilizou-se o delineamento inteiramente casualizado, e os valores obtidos foram submetidos à análise de variância pelo teste $\mathrm{F}$ e comparação das médias pelo teste de Tukey, conforme descrito por Gomes (2002).

\section{Resultados e discussão}

\subsection{Percentuais de frutos e área afetada com manchas na polpa}

Até 20 dias de armazenamento nenhum fruto apresentava mancha escura na polpa, porém, após este período, manchas transparentes foram observadas em $42 \%$ dos frutos que receberam doses de 100 e 150 Gy e $25 \%$ dos frutos controle. Embora o percentual de frutos controle afetados tenha sido menor, a proporção de área afetada foi duas vezes maior quando comparada com os que receberam dose de 150 Gy nesse mesmo período de armazenamento (Figuras 1a e 1b).

Observou-se que com 30 dias de armazenamento, o número de frutos afetados com transparência e manchas escuras era de $100 \%$ para todos os frutos que foram irradiados e para o controle também. Os valores encontrados não se mostraram significativos entre as doses, no entanto, o tempo de armazenamento foi um fator importante no aumento da área afetada, em que se observou um aumento de seis e nove vezes maior entre os intervalos de 20 e 30 dias nos frutos que receberam doses de 100 e $150 \mathrm{~Gy}$, respectivamente. Pode ser observado ainda que no final do armazenamento a radiação ionizante agravou esse distúrbio
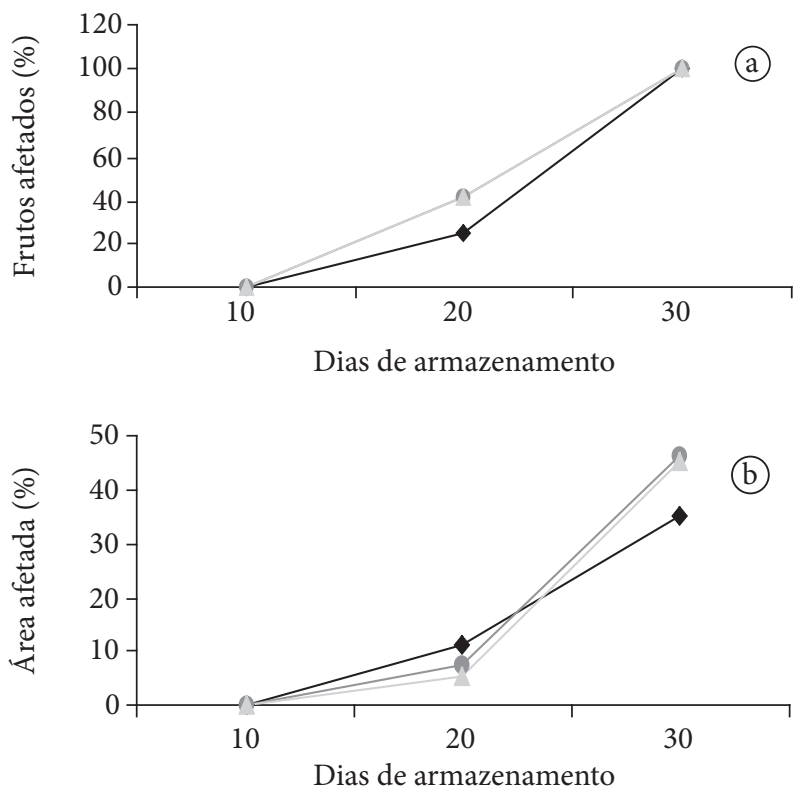

Figura 1. Valores médios percentuais de frutos afetados (a) e área afetada (b) com mancha na polpa em abacaxi submetido a diferentes doses de radiação gama e armazenados durante dez, vinte e trinta dias sob temperatura de $12{ }^{\circ} \mathrm{C}( \pm 1)$ e $85 \%( \pm 5)$ de UR. Estatística: a) Tempo: $\mathrm{F}=48,08^{\star *}$, Dose: $\mathrm{F}=0,37 \mathrm{~ns}$; b) Tempo: $\mathrm{F}=49,01^{\star *}$, Dose: $\mathrm{F}=0,20$ ns. ns = não significativo; $\mathrm{e}^{\star *}=$ significativo a $1 \%$ pelo teste de Tukey.

fisiológico, provavelmente pelos maiores efeitos do produto da radiólise devido ao alto teor de umidade do abacaxi.

\subsection{Cor da polpa}

Valores próximos a 70, indicando uma boa luminosidade da polpa (valor de $\mathrm{L}^{\star}$ ), foram encontrados para todas as doses estudadas com 20 dias de armazenamento (Figura 2a). Por outro lado, menor luminosidade e, portanto, maior escurecimento da polpa foi encontrado com 30 dias de armazenamento, com média geral significativa em relação aos demais intervalos.

Valores de $\mathrm{a}^{*}$ nos frutos irradiados com doses de $100 \mathrm{e}$ $150 \mathrm{~Gy}$ foram menores nos dois primeiros intervalos de armazenamento (Figura 2b), representado por uma cor menos amarelada nesses frutos, o que indica uma menor maturação. Entretanto, com 30 dias de armazenamento os frutos irradiados com dose de 150 Gy obtiveram as maiores médias. Esse resultado pode estar associado às presenças das manchas, que nesses frutos foram maiores nesse período.

Frutos controle obtiveram as maiores médias em todos os períodos avaliados para os valores de $b^{*}$ (Figura $2 c$ ), com cor mais amarelada, indicativo de um estágio mais avançado de maturação, o que só vem a corroborar com os resultados encontrados para cor da casca, já que a cor da casca desses frutos se mostrava mais amarela (valores não mostrados). 

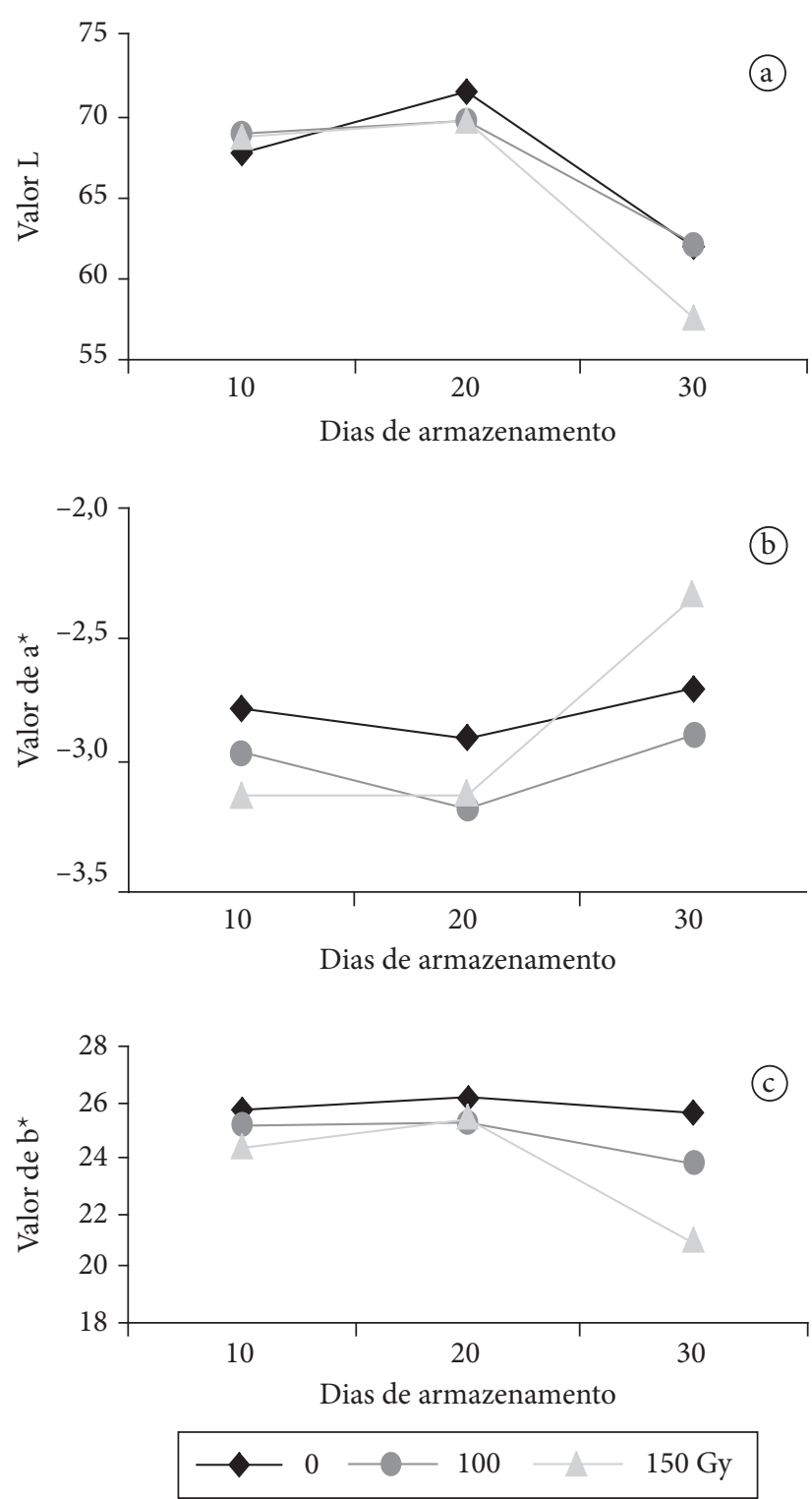

Figura 2. Valores médios de L (a), $a^{*}(b)$ e $b^{*}(c)$ para cor da polpa inteira em abacaxi submetido a diferentes doses de radiação gama e armazenados durante dez, vinte e trinta dias sob temperatura de $12{ }^{\circ} \mathrm{C}( \pm 1)$ e $85 \%( \pm 5)$ de UR. Estatística: a) Tempo: $\mathrm{F}=25,57^{\star *}$, Dose: $\mathrm{F}=0,79$ ns: b) Tempo: $\mathrm{F}=6,07^{\star}$, Dose: $\mathrm{F}=1,42 \mathrm{~ns} ; \mathrm{c}$ ) Tempo: $\mathrm{F}=2,57^{\star}$, Dose: $\mathrm{F}=2,62$ ns. $\mathrm{ns}=$ não significativo; ${ }^{*}=$ significativo a $5 \% ; \mathrm{e}^{\star *}=$ significativo a $1 \%$ pelo teste de Tukey.

\subsection{Firmeza da polpa, sólidos solúveis totais, acidez total titulável e potencial hidrogeniônico}

Maior firmeza da polpa foi encontrada nos frutos irradiados durante todo período de armazenamento. A maior diferença entre as doses aplicadas foi encontrada com 10 dias, quando frutos controle apresentaram média de $35,86 \mathrm{~N}$ e frutos que receberam dose de 150 Gy com 40,89 N (Figura 3a).

Resultados semelhantes foram relatados por Damayanti, Sharma e Kundu (1992), quando afirmaram que abacaxis irradiados com dose de $150 \mathrm{~Gy}$ e armazenados sob 25 a $28^{\circ} \mathrm{C}$
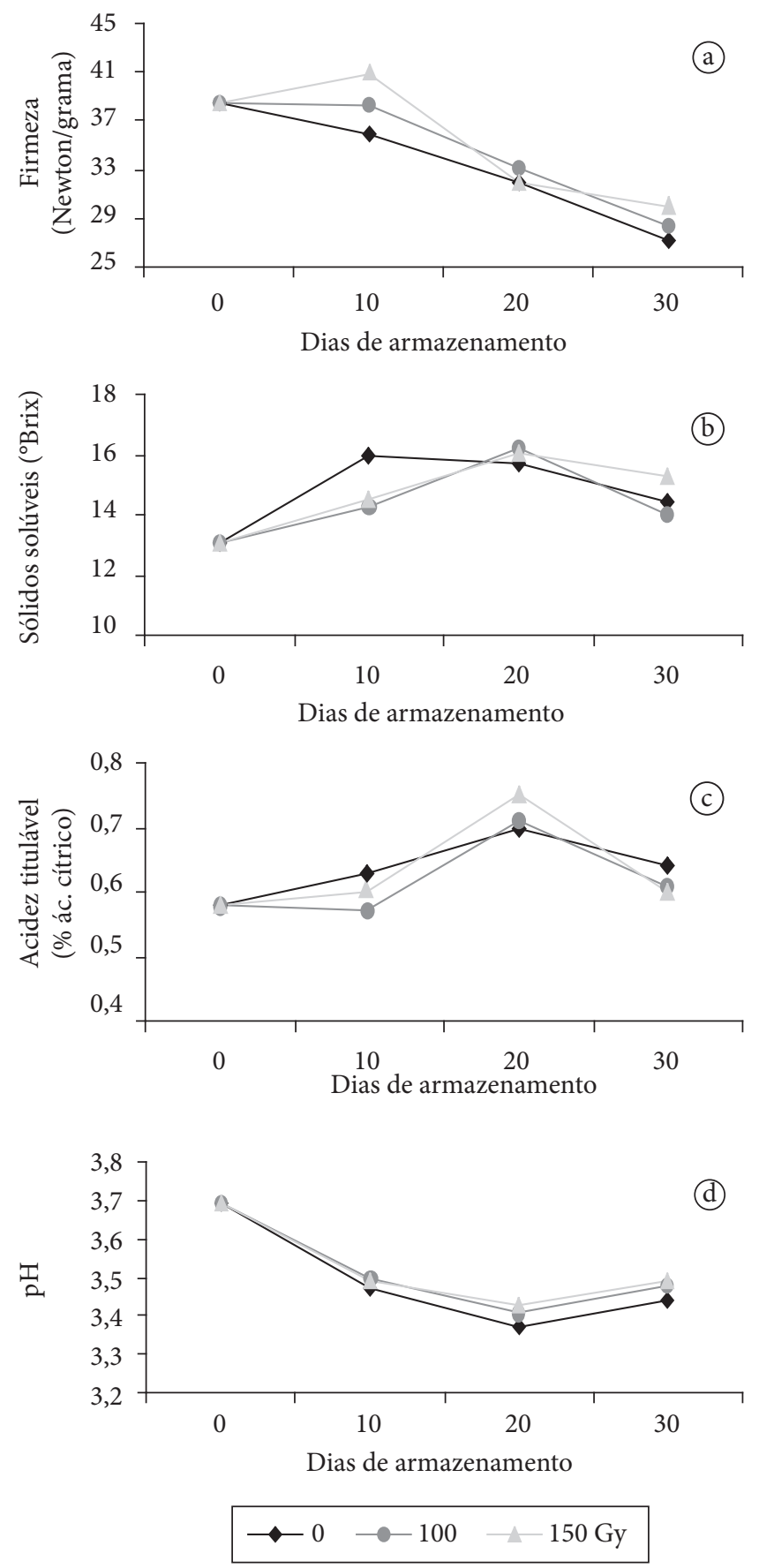

Figura 3. Valores médios da firmeza da polpa (a), sólidos solúveis totais (b), acidez total titulável (c) e potencial hidrogeniônico (pH) (d) em abacaxi submetido a diferentes doses de radiação gama e armazenado durante dez, vinte e trinta dias sob temperatura de $12{ }^{\circ} \mathrm{C}( \pm 1)$ e $85 \%( \pm 5)$ de UR. Estatística: a) Tempo: $\mathrm{F}=13,32^{\star}$, Dose: $\left.\mathrm{F}=0,92 \mathrm{~ns}\right)$; b) Tempo: $\mathrm{F}=4,37^{\star}$, Dose: $\mathrm{F}=0,63 \mathrm{~ns} ; \mathrm{c}$ ) Tempo: $\mathrm{F}=8,77^{\star}$, Dose: $\mathrm{F}=0,29 \mathrm{~ns} ; \mathrm{d}$ ): Tempo: $\mathrm{F}=4,72^{*}$, Dose: $\mathrm{F}=1,15$ ns. $\mathrm{ns}=$ não significativo; $\mathrm{e}^{*}=$ significativo a $5 \%$ pelo teste de Tukey.

mantiveram melhor textura ao serem comparados com frutos controle. Também Susheela, Damayanti e Sharma (1997), ao processarem abacaxis com doses de 50 a 250 Gy sob temperatura de 25 a $29^{\circ} \mathrm{C}$, constataram melhor textura quando comparados com os frutos controle. 
Observa-se ainda uma redução gradual da firmeza durante o período de armazenamento. Perdas de 24,26 e $27 \%$ da firmeza para frutos controle e irradiados com doses de 100 e $150 \mathrm{~Gy}$, respectivamente, foram encontradas entre o intervalo de $10 \mathrm{e}$ 30 dias, o que indica a influência do tempo sobre essa característica do fruto. Segundo Chitarra e Chitarra (1990), perda na qualidade textural durante o amadurecimento é resultado das alterações do conteúdo das pectinas e outros polímeros constituintes da parede celular, além da ação das enzimas de degradação da parede celular, que se tornam mais atuantes com o amadurecimento, conduzindo o fruto de um estado aceitável para o consumo, a um estado inaceitável.

Maior quantidade dos sólidos totais foi encontrada nos frutos controle com 10 dias de armazenamento (Figura 3b), essa maior quantidade está associada com o grau de maturação desses frutos, concordando com o resultado da cor da polpa descrito anteriormente. Observa-se em todas as doses um aumento e depois uma redução nos teores dos sólidos totais com o tempo de armazenamento, podendo estar relacionados com a hidrólise dos polissacarídeos insolúveis, principalmente do amido a açúcares solúveis, como também a degradação dos açúcares em outras funções metabólicas do amadurecimento (CHITARRA; CHITARRA, 1990).

É importante ressaltar, que os valores encontrados para todas as doses e períodos estudados, principalmente com 20 dias, foram bem maiores que os exigidos para o mercado externo, que exige valores superiores a $12{ }^{\circ}$ Brix para o tipo 'fruto Fancy' (Extra) (GARCIA et al., 1996).

Os maiores valores da acidez titulável foram obtidos com 20 dias de armazenamento (Figura 3c), porém, não ocorreram diferenças significativas entre as diferentes doses estudadas.

Nos frutos geralmente ocorre redução dos ácidos com o tempo de armazenamento, em decorrência do seu consumo para as reações próprias da maturação e senescência. Uma significativa redução dos ácidos entre o intervalo de 20 e 30 dias pode ser observada, na qual pode ter ocorrido seu consumo, portanto, menor quantidade para a síntese de novas reações, uma vez que os frutos apresentavam-se com maturação bastante avançada no final do experimento.

Valores menores encontrados no ponto de colheita podem ser atribuídos ao consumo dos ácidos para correções de pequenos danos físicos causados normalmente durante o processo de colheita, transporte e instalação do experimento, provavelmente por ter ocorrido um aumento da respiração durante essas etapas (MEDLICOTT; JEGER, 1987).

Pequenas variações nos valores do potencial hidrogeniônico $(\mathrm{pH})$ para as diferentes doses aplicadas durante o período de armazenamento foram encontradas (Figura 3d). Mesmo pequenas variações nessa característica podem causar alterações acentuadas no sabor do fruto.

Valores menores do $\mathrm{pH}$ foram encontrados com 20 dias de armazenamento, apresentando média geral das doses estudadas com 3,40, diferenciando estatisticamente da média geral do intervalo de 10 dias com 3,48. Essa redução correspondeu ao aumento da acidez titulável nesse mesmo período. Souto et al.
(2004) verificaram que a cultivar Pérola armazenada sob temperatura de $8{ }^{\circ} \mathrm{C}$ apresentou o mesmo comportamento.

\subsection{Razão sólidos solúveis/acidez titulável e teor de ácido ascórbico}

Menores valores da razão sólidos solúveis/acidez titulável foram encontrados nos frutos irradiados com dose $150 \mathrm{~Gy}$ com 20 dias de armazenamento (Figura 4a), esse resultado pode estar associado ao maior teor dos ácidos encontrados nesses frutos. Foi encontrada redução considerável entre os intervalos de 10 e 20 dias, com elevação entre os intervalos de 20 e 30 dias, esse último resultado pode estar associado ao estado de maturação no final do experimento, onde ocorreu o decréscimo dos ácidos. Neto et al. (1996) relataram que independente da temperatura de armazenamento ocorreu decréscimo na razão sólidos solúveis/acidez titulável do abacaxi durante o período de armazenamento.

Apenas com 10 dias de armazenamento, os teores de vitamina $\mathrm{C}$, avaliados pelo teor de ácido ascórbico, foram um pouco maiores nos frutos irradiados, quando apresentaram valores de 14,59 e $14,45 \mathrm{mg} .100 \mathrm{~mL}^{-1}$ de suco do que os com doses de 100 e 150 Gy, respectivamente. No entanto, com 20 dias de armazenamento o fruto controle apresentou o maior valor de
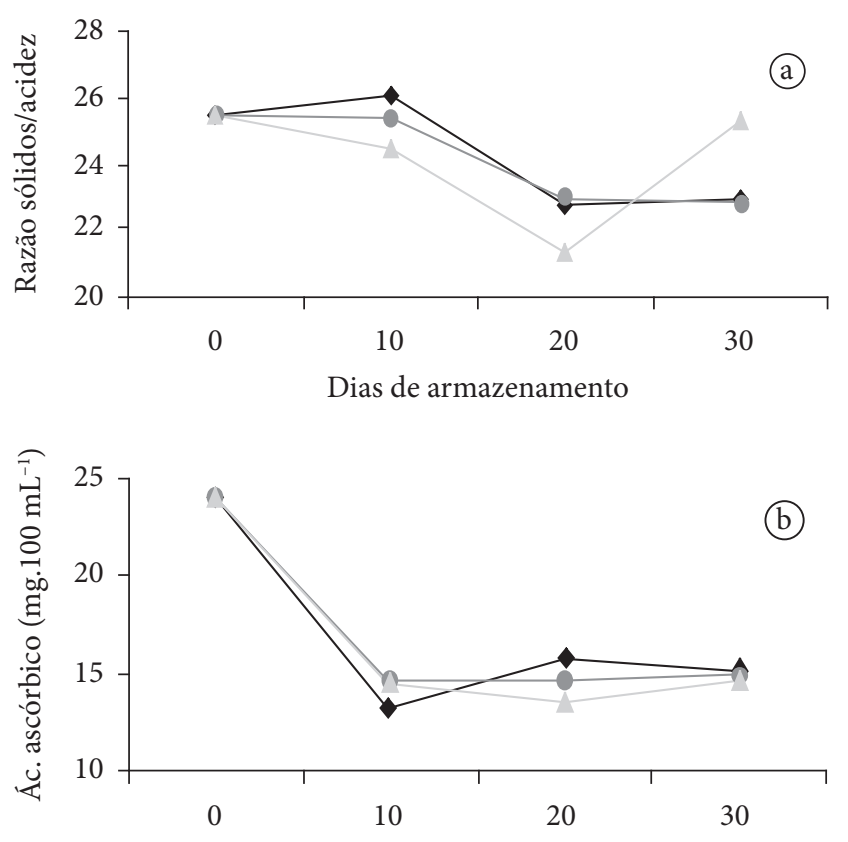

Dias de armazenamento

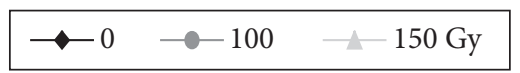

Figura 4. Valores médios da razão sólidos/acidez (a) e teor de ácido ascórbico (b) em abacaxi submetido a diferentes doses de radiação gama e armazenado durante dez, vinte e trinta dias sob temperatura de $12{ }^{\circ} \mathrm{C}( \pm 1)$ e $85 \%( \pm 5)$ de UR. Estatística: a) Tempo: $\mathrm{F}=2,14 \mathrm{~ns}$, Dose: $\mathrm{F}=0,01 \mathrm{~ns}$; b) Tempo $\times$ Dose: $\mathrm{F}=3,81^{\star}$. ns = não significativo; $\mathrm{e}^{*}=$ significativo a $5 \%$ pelo teste de Tukey. 
15,85 , sendo significativamente diferente dos que receberam dose de 150 Gy com 13,51 (Figura 4b).

Perda considerável ocorreu entre o ponto de colheita e os primeiros 10 dias de armazenamento, com redução maior que $45 \%$ nos frutos controle. Essa perda pode ser atribuída à degradação ou utilização desse ácido nos primeiros dias pósamadurecimento fisiológico, podendo também estar associada ao estresse físico do transporte, aplicação do tratamento e instalação do experimento.

A análise de variância mostrou interação entre os fatores estudados onde o tempo de armazenamento foi significativo para 10 dias em relação aos demais períodos, e as doses para frutos controle em relação aos com 150 Gy. Lee e Kader (2000) afirmam que doses menores de $1 \mathrm{kGy}$ não têm efeito significativo no índice de vitamina $\mathrm{C}$ de diversos frutos e vegetais. Susheela, Damayanti e Sharma (1997), ao irradiarem abacaxis com doses de 50 a $250 \mathrm{~Gy}$, sob temperatura de 25 a $29^{\circ} \mathrm{C}$ e UR de 90 a $97 \%$, não constataram diferenças significativas nas perdas do ácido ascórbico.

Valores bem maiores do ácido ascórbico foram encontrados por Silva (1997), ao trabalhar com essa mesma cultivar armazenada por 30 dias sob temperatura de $8,5^{\circ} \mathrm{C}$, quando relatou valores entre 27 a $30 \mathrm{mg}$ por $100 \mathrm{~mL}$ de suco, porém, Gonçalves e Carvalho (2003) afirmam que, no geral, em abacaxi os teores desse ácido ficam em torno de $17 \mathrm{mg} .100 \mathrm{~mL}^{-1}$.

\subsection{Teores das clorofilas $a, b$ e total na casca}

Frutos irradiados apresentaram maiores valores das clorofilas a, b e total com 10 dias de armazenamento (Figuras 5a, $5 \mathrm{~b}$ e $5 \mathrm{c}$ ). Os valores encontrados para clorofila total foram de 232,13 e 223,94 $\mu \mathrm{g} . \mathrm{g}^{-1}$ de casca fresca nos frutos que receberam as doses de 100 e $150 \mathrm{~Gy}$, respectivamente, enquanto que nos frutos controle o valor foi de $152,12 \mu \mathrm{g} \cdot \mathrm{g}^{-1}$ de casca fresca, com diferença significativa entre os que foram irradiados e os frutos controle.

Observa-se um comportamento semelhante das clorofilas para todas as doses estudadas, quando apresentam degradação progressiva com o tempo de armazenamento. Esse resultado se atribui à ação da enzima clorofilase que se torna bastante atuante com o avanço do amadurecimento do fruto (YAMAUCHI; WATADA, 1991).

Para todas as clorofilas, a partir de 20 dias de armazenamento, os valores nos frutos controle apresentaram-se maiores, o que pode ser afirmado que a radiação ionizante teve efeito apenas de retardar a degradação das clorofilas.

Os valores também revelam uma redução acentuada nas clorofilas entre o ponto de colheita até os 10 primeiros dias de armazenamento, com reduções médias das clorofilas a, b e total de 64,68 e $66 \%$ para os frutos controle, respectivamente.

\section{Conclusões}

Os resultados encontrados no presente trabalho nos permitiram chegar às seguintes conclusões:
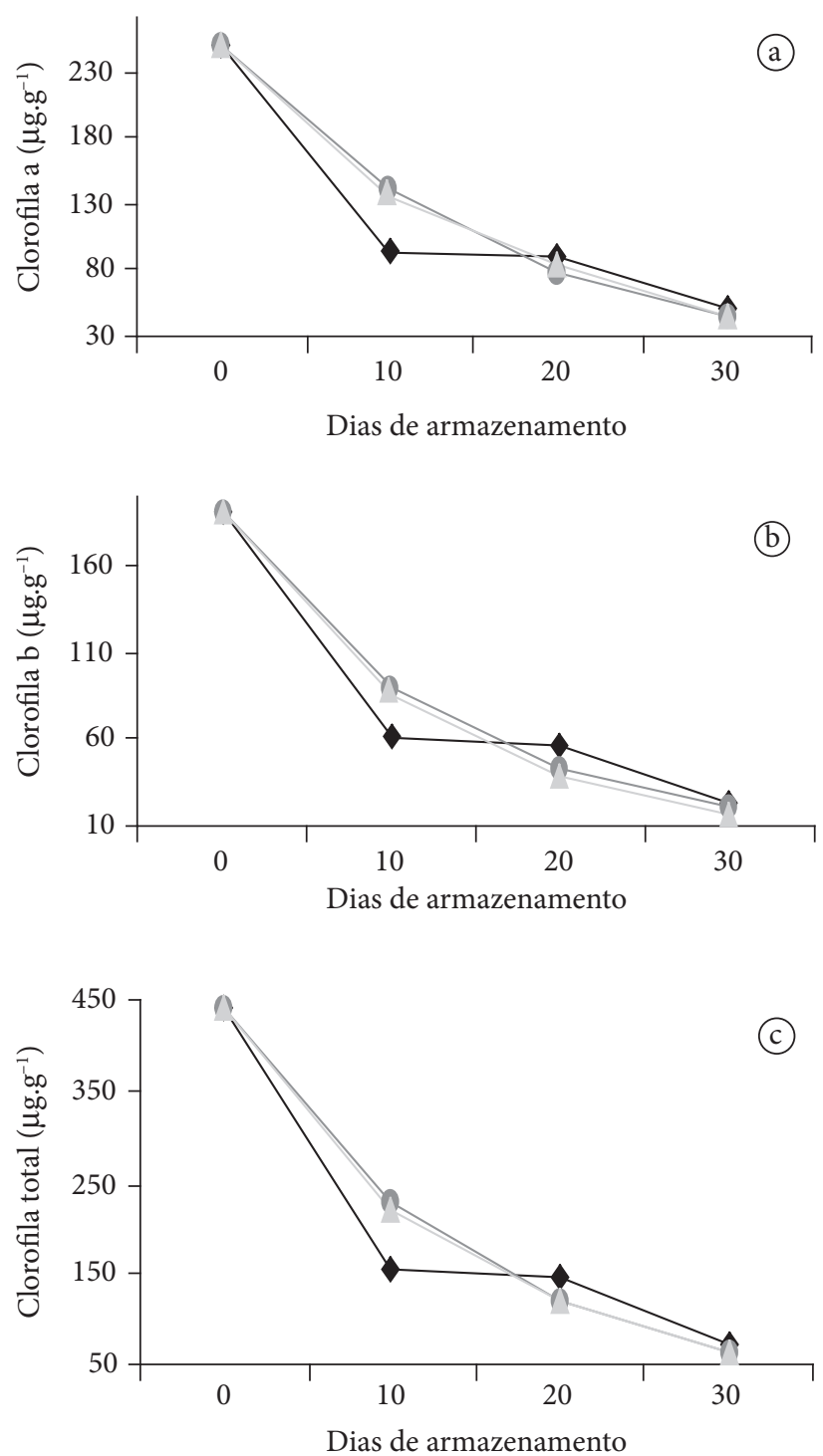

$$
\longrightarrow 0-100-150 \mathrm{~Gy}
$$

Figura 5. Valores médios dos teores das clorofilas a (a), b (b) e total (c) em abacaxi submetido a diferentes doses de radiação gama e armazenado durante dez, vinte e trinta dias sob temperatura de $12{ }^{\circ} \mathrm{C}( \pm 1)$ e $85 \%$ ( \pm 5$)$ de UR. Estatística: a) Tempo x Dose: $F=2,98^{*}$; b) Tempo $\times$ Dose: $\mathrm{F}=2,91^{\star}$; c) Tempo $\times$ Dose: $\mathrm{F}=2,93^{\star} .{ }^{*}=$ significativo a $5 \%$ pelo teste de Tukey.

- As doses de 100 e 150 Gy tiveram pouca influência significativa nas características físico-químicas do abacaxi, entretanto, frutos irradiados apresentaram os melhores resultados quanto à conservação das características póscolheita;

- O período de 20 dias de armazenamento foi ideal para o consumo humano devido aos maiores valores dos sólidos solúveis totais e da acidez total titulável, características essenciais na determinação do sabor dessa cultivar;

- O armazenamento até 30 dias sob as condições estabelecidas no presente experimento foi considerado longo 
devido ao fato de prejudicar as principais características de qualidade do fruto;

- Os frutos irradiados com dose de 100 Gy obtiveram melhores resultados nas características físico-químicas analisadas quando comparados com os resultados encontrados nos frutos irradiados com dose de $150 \mathrm{~Gy}$; e

- Outras pesquisas devem ser realizadas com o objetivo de avaliar outros fatores externos ao fruto para que se possa chegar a uma conclusão mais exata quanto à aplicabilidade dessa tecnologia no abacaxi.

\section{Agradecimentos}

Os autores agradecem à Fundação de Amparo à Pesquisa do Estado de São Paulo - FAPESP, pelo apoio financeiro para realização do presente trabalho, ao Centro de Energia Nuclear na Agricultura - CENA/USP e à Escola Superior de Agricultura Luiz de Queiroz - ESALQ/ Universidade de São Paulo - USP, pela oportunidade de realização da pesquisa.

\section{Referências bibliográficas}

ARNON, D. I. Copper enzymes in isolated chloroplasts. Polyphenoloxidase in Beta vulgaris. Plant Physiology, v. 24, n. 1, p. 1-15, 1949.

BRASIL. Ministério da Agricultura e do Abastecimento. Secretaria de Produção e Comercialização. Departamento de Comercialização. Balança Comercial do Agronegócio. Brasília, DF. 2000. 25 p.

CARVALHO, C. R. L. et al. Análises químicas de alimentos. Campinas: ITAL, 1990. 121 p. (Manual Técnico).

CHITARRA, M. I. F.; CHITARRA, A. B. Pós-colheita de frutos e hortaliças: fisiologia e manuseio. Lavras: ESAL, FAEP, 1990.

DAMAYANTI, M.; SHARMA, G. J.; KUNDU, S. C. Gamma radiation influences postharvest disease incidence of pineapple fruits. HortScience, St. Joseph, v. 27, n. 7, p. 807-808, 1992

DEL MASTRO, N. L. Development of food irradiation in brazil. Progress in Nuclear Energy, New York, v. 35, n. 3-4, p. 229-248 1999.

FINGER, F.; VIEIRA, G. Introdução à fisiologia pós-colheita de produtos hortícolas. In: CONGRESSO BRASILEIRO DE FISIOLOGIA VEGETAL. 6. 1997, Belém. Resumos... Belém: CENTUR, 1997. p. 83.

GARCIA, E. E. C. et al. Abacaxi para exportação: Embalagem. Brasília: MAARA; EMBRAPA, SPI, 1996. 41 p. (Série Publicações Técnicas FRUPEX, 23).

GOMES, F. P. Estatística aplicada a experimentos agronômicos e florestais. Piracicaba: FEALQ, 2002.

GONÇALVES, N. B.; CARVALHO, V. D. Características do abacaxi. Toda Fruta, Edição de 13 dez. 2002. Disponível em: <www.todafruta. com.br/todafruta/mostra_conteudo.asp? conteudo $=1060>$. Acesso em: 20 dez. 2003.

IAL. Instituto Adolfo Lutz. Normas analíticas do Instituto Adolfo Lutz. 3. ed. São Paulo, 1985. 533 p.
LEE, S. K.; KADER, A. A. Preharvest and postharvest factors influencing vitamin $\mathrm{C}$ content of horticultural crops. Postharvest Biology and Technology, Amsterdam, v. 20, n. 3, p. 207-220, 2000.

MARIN-HUACHACA, N. S. et al. Detection of irradiated fresh fruits treated by e-beam or gamma rays. Radiation Physics and Chemistry, Oxford, v. 63, n. 3-6, p. 419-422, 2002.

McGUIRRE, R. G. Reporting of objective color measurents. HortScience, St. Joseph, v. 27, n. 12, p. 1254-1255, 1992.

MEDLICOTT, A. P.; JEGER, M. J. The development and application of postharvest handling treatment to manipulate ripening in mangoes. In: PINSLEY, R. T.; TUCKER, R. T. Mangoes: a review. London: Commonwealth Science Council, 1987. p. 56-77.

MORGADO, I. F.; AQUINO, C. N. P.; TERRA, D. C. T. Aspectos econômicos da cultura do abacaxi: sazonalidade de preços no Estado do Rio de Janeiro. Revista Brasileira de Fruticultura, Cruz das Almas, v. 26, n. 1, p. 44-47, 2004.

MURRAY, D. R. Biology of food irradiation. London: Research Studies Press, 1990. 255 p.

NETO, J. P. L. Brasil Nuclear, Rio de Janeiro, n. 15, p. 4-5, 1997.

NETTO, A. G. et al. Abacaxi para exportação: procedimentos de colheita e pós-colheita. Brasília: MAARA, 1996. 41 p. (Série Publicações Técnicas FRUPEX, 23).

PCZCZOLA, D. E. Irradiated produce reaches Midwest market. Food Technology, Champaign, v. 45, n. 5, p. 89-92, 1992.

PONTES THÉ, P. M. et al. Modificações na atividade enzimática em abacaxi'Smooth Cayenne' em função da temperatura de armazenamento e do estádio de maturação. Ciência Agrotécnica, Lavras/MG, v. 25, n. 2, p. 364-370, 2001.

PY, C.; TISSEAU, M. A. L'ananas. Paris: Maisonneuve et Larose. 1965.

SILVA, J. M. Uso de atmosfera modificada no armazenamento do abacaxi Cv. Smooth Cayenne. Lavras, 1997. 97 p. Dissertação (Mestre em Fisiologia Vegetal) - Universidade Federal de Lavras (UFLA/MG).

SILVA, J. M.; Domarco, R. E. Análise visual dos efeitos da radiação associada à atmosfera modificada no armazenamento do limão 'Tahiti' - Ensaio preliminar. Revista Brasileira de Pesquisa e Desenvolvimento, São Paulo, v. 4, n. 3, p. 1518-1523, 2004.

SOUTO, R. F. et al. Conservação pós-colheita de abacaxi 'Pérola' colhido no estádio de maturação "pintado" associando-se refrigeração e atmosfera modificada. Revista Brasileira de Fruticultura, Cruz das Almas, v. 26, n. 1, p. 24-28, 2004.

SUSHEELA, K.; DAMAYANTI, M.; SHARMA, G. J. Irradiation of Ananas comosus: shelf life improvement, nutritional quality and assessment of genotoxicity. Biomedical Letters, v. 56, p. 223-224, 1997.

YAMAUCHI, N.; WATADA, A. E. Regulated chlorophyll degradations in spinach leaves during storage. Journal of American Society of Horicultural Science, Alexandria, v. 116, n. 1, p. 58-62, 1991.

YANG, S. F.; HOFFMAN, N. E. Ethylene biosynthesis and its regulation in higher plant. Annual Review of Plant Physiology, Palo Alto, v. 35 , p. $155-189,1984$. 